\title{
Clinical outcomes of patients undergoing primary percutaneous coronary intervention for acute myocardial infarction requiring the intensive care unit
}

Ken Parhar ${ }^{1,3^{*}}$ (D) Victoria Millar ${ }^{1}$, Vasileios Zochios ${ }^{1,4}$, Emilia Bruton ${ }^{1}$, Catherine Jaworksi ${ }^{2}$, Nick West ${ }^{2}$ and Alain Vuylsteke

\begin{abstract}
Background: Outcomes for patients with ST-segment elevation myocardial infarction continue to improve, largely due to timely provision of reperfusion by primary percutaneous coronary intervention (PPCl). However, despite prompt and successful PPCl, a small proportion of patients require ventilatory and hemodynamic support in an intensive care unit (ICU). The outcome of these patients remains poorly defined.

Methods: A retrospective review of all consecutive admissions post-PPCI pathway to a single ICU between January 2009 and May 2014 was performed. Patients were analysed based on survival and indication for admission.

Preadmission characteristics and ICU course were reviewed. Univariate and multivariable regression analysis was performed to determine predictors of outcome.

Results: During the study period 2902 PPCI were performed and 101 patients were admitted to ICU following PPCI (incidence 3.5\%). ICU mortality post-PPCI was 33.7\%. Pre-ICU admission factors in a multivariable logistic regression analysis associated with increased mortality included requirement for an intra-aortic balloon pump and a high SOFA score.

Conclusions: ICU admission post PPCI is associated with significant mortality. Mortality was related to high presenting SOFA score and need for IABP. These results provide important prognostic information and an acceptable method for risk-stratifying patients with acute myocardial infarction requiring intensive care.
\end{abstract}

Keywords: Acute myocardial infarction, Primary percutaneous coronary intervention, Mechanical ventilation, Intensive care unit

\section{Background}

Acute myocardial infarction, in particular ST-segment elevation myocardial infarction (STEMI) remains a timesensitive medical emergency associated with significant morbidity and mortality [1]. In recent years, the widespread recognition of primary percutaneous coronary intervention (PPCI) as an evidence-based treatment strategy that can improve outcomes has led to both an

\footnotetext{
* Correspondence: ken.parhar@albertahealthservices.ca

'Department of Anesthesia and Intensive Care, Papworth Hospital, Cambridge, England

${ }^{3}$ Department of Critical Care Medicine, University of Calgary, ICU Administration - Ground Floor - McCaig Tower, Foothills Medical Center, 3134 Hospital Drive NW, Calgary, AB T2N 5A1, Canada

Full list of author information is available at the end of the article
}

increase in PPCI volume and a reduction in hospital mortality associated with STEMI [2,3]. A major driver to facilitate this has been the creation and implementation of organised PPCI networks that are able to triage and deliver patients directly to centres able to routinely provide this service both in- and out-of-hours [4, 5]. Patients are subsequently generally cared for in a coronary-care unit (CCU), which has been shown to reduce mortality [6].

The National Infarct Angioplasty Project has demonstrated the benefits of PPCI over thrombolysis for treatment of STEMI patients [7] and has led to the creation of PPCI centres across England. By 2013, some regions demonstrated that more than $95 \%$ of patients treated for 
STEMI received PPCI, compared with only $30 \%$ in the third quarter of 2008 [5].

Despite the pervasiveness of PPCI in the management of STEMI and the appropriate use of CCU care, there remains a small proportion of patients that become critically ill and require advanced life support modalities post-PPCI, such as mechanical ventilation or vasoactive therapy that may only be provided within the intensive care unit (ICU). Historically, patients with a complicated myocardial infarction requiring mechanical ventilation have been associated with high rates of morbidity and mortality [8-13].

Patients that may require ICU post-PPCI remain poorly defined. This retrospective single-centre cohort review aims to describe the incidence of admission to ICU, indication for ICU admission, and quantify the morbidity and mortality associated with ICU admission. In addition, factors associated with survival are assessed.

\section{Methods}

\section{Patient population}

We undertook a retrospective review of all consecutive patients admitted to a single tertiary cardiothoracic ICU post-PPCI between January 2009 and May 2014. The unit is the sole provider of intensive care in a subspecialty cardiothoracic hospital serving an English region with a catchment area of approximately three million. All patients requiring PPCI in this region are transferred to this institution.

The search was performed via the electronic Clinical Information System (CIS), which maintains the electronic medical record of all patients admitted to ICU. The initial search yielded 191 patients. Patients were excluded if not admitted directly post-PPCI. Ninety patients were excluded including: patients admitted immediately before or after cardiac surgery or cardiac procedures other than PPCI $(n=78)$, post respiratory medicine procedures $(n=2)$, patients admitted due to lack of beds in CCU $(n=9)$, and patients admitted for end of life care $(n=1)$. A total of 101 patients post-PPCI were appropriate for detailed chart review and analysis (Fig. 1).

\section{Clinical data}

Demographic data (including age, gender, past medical history, and cardiovascular risk factors) were extracted from case-notes and the electronic CIS. Baseline physiological characteristics (vital signs, Glasgow coma scale (GCS), laboratory values) were extracted from the electronic CIS. Details related to PPCI admission, echocardiograms, and cardiac catheterization (downtime, location of infarction, procedures performed, anatomy of coronary disease, complications, door-to-balloon time, pre-PCI interventions) were extracted from a dedicated local database (Philips CVIS, Netherlands), routinely collected for national audits, and patient case-notes where appropriate. ICU interventions, length of stay, and complications were extracted from CIS. Survival data including the ICU and 28 day/hospital outcome was derived from both CIS, case notes and local databases linked to national outcome data.

Vital signs on admission (including heart rate, blood pressure and mean arterial pressure) are reported as mean over the first $24 \mathrm{~h}$ of ICU admission. The admission $\mathrm{PaO} 2$ to $\mathrm{FiO} 2(\mathrm{PF})$ ratio, creatinine, platelets, bilirubin were the worst value measured over the first $24 \mathrm{~h}$. Pulmonary edema was defined as hypoxemia with associated radiographic evidence of interstitial and/or alveolar edema. Cardiogenic shock was defined as a systolic blood pressure $<90 \mathrm{mmHg}$ with clinical evidence of hypoperfusion (cyanosis, mottling, oliguria, cold extremities) or the requirement for an inotrope. New onset renal dysfunction was defined as a $25 \%$ rise in serum creatinine or the requirement for renal replacement therapy. The initiation of renal replacement therapy was based on refractory hyperkalemia, refractory acidosis, or volume overload despite medical management. Major hemorrhage was clinical evidence of bleeding with the requirement for four or more units of red blood cells. Infection was a positive culture result, or clinical syndrome consistent with infection such as pneumonia (fever, elevated white cell count, purulent sputum, hypoxemia). Sequential organ function failure assessment (SOFA) score was calculated as previously described $[14,15]$.

\section{Groups}

Patient outcomes were analysed based on ICU survival. Patient were stratified and analysed based on one of four indications for ICU admission including out-of-hospital cardiac arrest (OHCA), in-hospital cardiac arrest (IHCA), cardiogenic shock, or pulmonary edema. IHCA was defined as a cardiac arrest occurring following arrival to hospital (most commonly during cardiac catheterization), but prior to admission to ICU. Cardiac arrests occurring while in ICU were listed as an ICU complication.

\section{Statistical analysis}

The Shapiro-Wilks test for normality was performed on all continuous variables. Continuous variables with normal distribution were reported as means with standard deviation and analysed by unpaired student's two-tailed $t$ test or one-way analysis of variance (ANOVA) where appropriate. Non-normally-distributed data were reported as median with interquartile range and analysed with the Mann-Whitney $U$ test or the Kruskal-Wallis test where appropriate. Categorical variables were analysed with the chi-squared test or Fisher's exact test where appropriate. A $p$ value of $<0.05$ was considered statistically significant. 


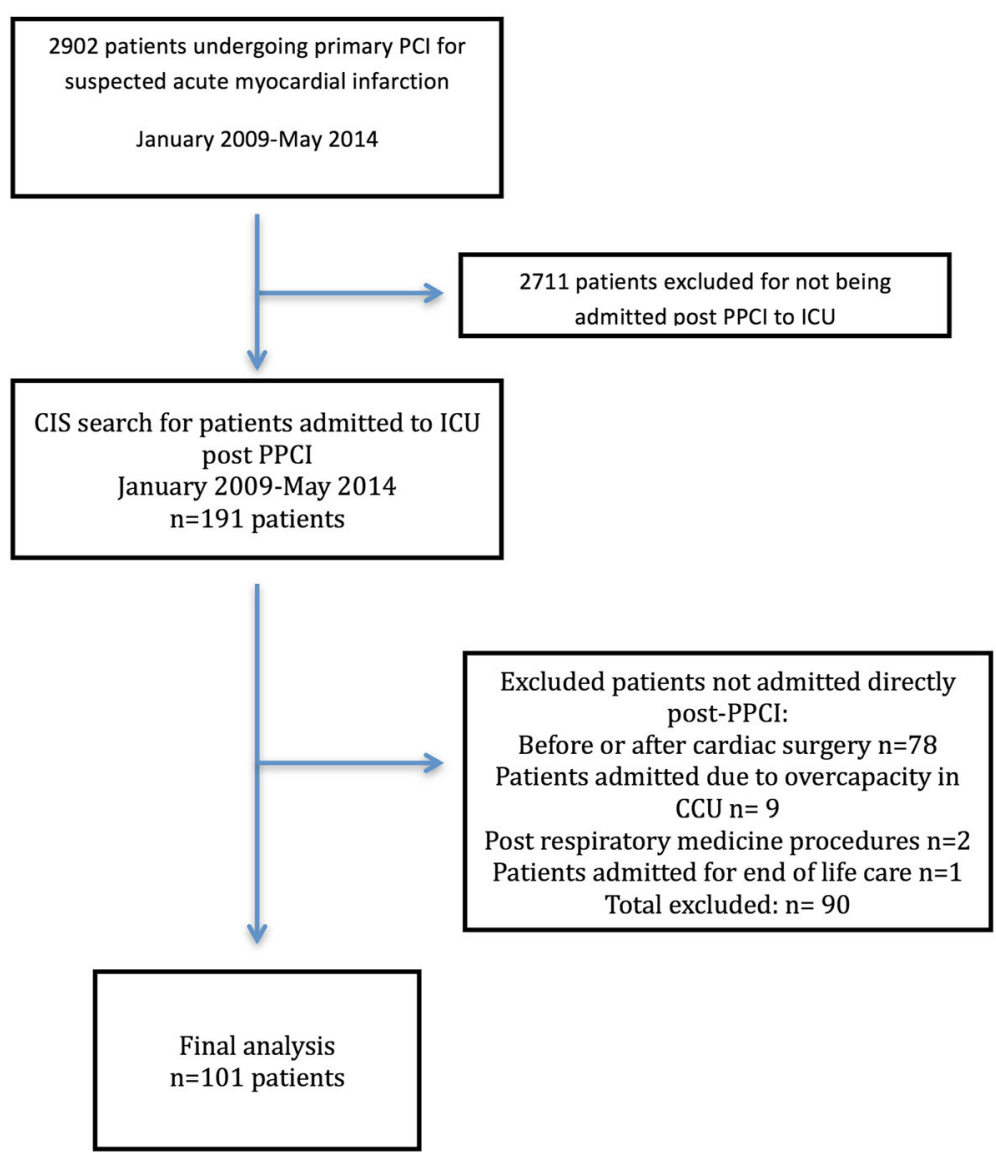

Fig. 1 Flowchart outlining patient selection

Variables that were statistically significant in the univariate analysis (with a $p$ value $<0.10$ ) were considered for inclusion in the multivariable logistic regression model. ICU mortality was defined as the dependant variable. Backward stepwise variable elimination was performed (with a variable exit threshold set at $p>0.05$ ). The performance of the final model was assessed using the area under the receiver-operating characteristic (AUROC) curve.

Statistical analysis was performed using Stata Version 13.1 (StataCorp, USA).

\section{Ethics}

Ethical approval was obtained from the Papworth Hospital NHS Foundation Trust research and development board for the completion of this study.

\section{Results}

One-hundred one patients met the inclusion criteria for this retrospective observational study (Fig. 1). During this time, a total of 2902 PPCI were performed, resulting in a post-PPCI incidence of admission to ICU post PPCI of $3.5 \%$
Of the 101 patients who were admitted to ICU, the majority were male (69\%), with a mean age of 65 years (Table 1). Out of hospital cardiac arrest (OHCA) was the most common indication for admission to ICU (36.6\%). A significant proportion of patients were admitted for inhospital cardiac arrest (IHCA; 31.7\%) and cardiogenic shock (22.8\%). The least common indication for admission to ICU post-PPCI was pulmonary edema (8.9\%). Overall ICU mortality was $33.7 \%$ for the entire cohort.

Univariate factors that demonstrated a statistically significant difference between survivors and non-survivors included age, low blood pressure on admission (both systolic and mean arterial pressure), low PF ratio, low GCS, high creatinine, and high SOFA scores. In the subgroup of patients suffering from an OHCA, downtime before return of spontaneous circulation (ROSC) was statistically different between survivors and non-survivors. Survivors of ICU post PPCI were associated with a shorter downtime in comparison to non-survivors (Fig. 2). Patients who suffered a witnessed IHCA did not demonstrate a difference in time to ROSC between survivors and non-survivors. When patients were stratified based on their indication for admission (OHCA, IHCA, shock, or pulmonary edema) to ICU 
Table 1 Patient demographic factors for patients admitted to ICU post PPCI. Results are expressed as mean (SD) unless otherwise denoted

\begin{tabular}{|c|c|c|c|c|c|c|c|c|c|}
\hline & \multirow[t]{2}{*}{ All patients } & \multicolumn{3}{|l|}{ Outcome } & \multicolumn{5}{|l|}{ Indication for ICU } \\
\hline & & Survivor & Non-survivor & Sign & OHCA & IHCA & Card shock & Pulm edema & Sign \\
\hline Total no of patients (\%) & $101(100)$ & $67(66.3)$ & $34(33.7)$ & & $37(36.6)$ & $32(31.7)$ & $23(22.8)$ & $9(8.9)$ & \\
\hline Gender Male, no (\%) & $70(69.3)$ & $48(47.5)$ & $22(21.8)$ & 0.500 & $29(28.7)$ & $20(19.8)$ & $15(14.9)$ & $6(5.9)$ & 0.505 \\
\hline Age, years & $65.3(12.8)$ & $63.8(11.5)$ & $68.3(14.8)$ & 0.047 & $60.2(12.8)$ & $66.8(12.6)$ & $71.2(10.7)$ & $66.0(11.8)$ & 0.009 \\
\hline \multicolumn{10}{|l|}{ Cardiovascular risk factors } \\
\hline Smoking, no (\%) & $28(27.7)$ & $19(18.8)$ & $9(8.91)$ & 1.000 & $11(10.9)$ & $11(10.9)$ & $3(3.0)$ & $3(3.0)$ & 0.335 \\
\hline Diabetes mellitus, no (\%) & $21(20.8)$ & $10(9.9)$ & $11(10.9)$ & 0.067 & $4(4.0)$ & $7(6.9)$ & $8(7.9)$ & $2(2.0)$ & 0.171 \\
\hline Dyslipidaemia, no (\%) & $30(29.7)$ & $22(21.8)$ & $8(7.9)$ & 0.367 & $8(7.9)$ & $10(9.9)$ & $9(8.9)$ & $3(3.0)$ & 0.526 \\
\hline Hypertension, no (\%) & $58(57.4)$ & $40(39.6)$ & $18(17.8)$ & 0.531 & $18(17.8)$ & $17(16.8)$ & $16(15.8)$ & $7(6.9)$ & 0.229 \\
\hline \multicolumn{10}{|l|}{ Past medical history } \\
\hline Previous MI, no (\%) & $20(19.8)$ & $15(14.9)$ & $5(5.0)$ & 0.436 & $3(3.0)$ & $4(4.0)$ & $8(7.9)$ & $5(5.0)$ & 0.002 \\
\hline Previous CAD, no (\%) & $29(28.7)$ & $21(20.8)$ & $8(7.9)$ & 0.490 & $4(4.0)$ & $9(8.9)$ & $10(9.9)$ & $6(5.9)$ & 0.002 \\
\hline Previous CHF, no (\%) & $3(3.0)$ & $2(2.0)$ & $1(1.0)$ & 1.000 & $0(0.0)$ & $1(1.0)$ & $1(1.0)$ & $1(1.0)$ & 0.340 \\
\hline Renal failure, no (\%) & $12(11.9)$ & $8(7.9)$ & $4(4.0)$ & 1.000 & $3(3.0)$ & $2(2.0)$ & $5(5.0)$ & $2(2.0)$ & 0.210 \\
\hline COPD no, no (\%) & $11(10.9)$ & $9(8.9)$ & $2(2.0)$ & 0.326 & $3(3.0)$ & $6(5.9)$ & $0(0.0)$ & $2(2.0)$ & 0.096 \\
\hline \multicolumn{10}{|l|}{ Baseline characteristics on admission } \\
\hline $\mathrm{HR}(\mathrm{bpm})$ & $79.7(15.6)$ & $78.5(16.0)$ & $82.0(14.5)$ & 0.297 & $70.6(15)$ & $80.4(12.3)$ & $87.8(13.4)$ & $93.8(11.7)$ & $<0.001$ \\
\hline Systolic BP (mmHg) & $106.8(19.5)$ & $111.8(17.9)$ & $96.3(18.7)$ & $<0.001$ & $106.9(16.4)$ & $103.16(20.7)$ & $108.9(21.2)$ & $114.0(22.2)$ & 0.462 \\
\hline MAP (mmHg) & $73.0(13.0)$ & $77.7(10.3)$ & $63.7(12.9)$ & $<0.001$ & $72.5(12.4)$ & $73.7(15.3)$ & $71.4(9.5)$ & $77.0(15.0)$ & 0.720 \\
\hline $\mathrm{PaO2} / \mathrm{FiO} 2$ ratio, med (IQR) & $143(98-233)$ & $154(98-271)$ & $105(83-173)$ & 0.036 & $157.9(105-241)$ & $165(83-286)$ & $105(83-143)$ & $128(75-278)$ & 0.138 \\
\hline GCS, med (IQR) & $3(3-15)$ & $11(3-15)$ & $3(3-3)$ & $<0.001$ & $3(3-4)$ & $3(3-14.5)$ & $14(3-15)$ & $3(3-15)$ & 0.071 \\
\hline Serum creatinine $(\mu \mathrm{mol} / \mathrm{L})$, med $(\mathrm{IQR})$ & $116(87-157)$ & $102(84-129)$ & $156(115-203)$ & $<0.001$ & $101(71-126)$ & $116(95-155)$ & $140(112-191)$ & $135(117-144)$ & 0.012 \\
\hline SOFA score & $8.4(3.3)$ & $7.4(2.9)$ & $10.4(3.1)$ & $<0.001$ & $8.6(2.6)$ & $8.5(3.5)$ & $8.3(3.4)$ & $8.0(5.2)$ & 0.953 \\
\hline \multicolumn{10}{|l|}{ Indication for ICU admission } \\
\hline OHCA, no (\%) & $37(36.6)$ & $26(25.7)$ & $11(10.9)$ & 0.663 & & & & & \\
\hline Downtime before ROSC (min), (IQR) & $20(15-30)$ & $15(10-20)$ & $35(30-40)$ & $<0.001$ & & & & & \\
\hline IHCA, no (\%) & $32(31.7)$ & $19(18.8)$ & $13(12.7)$ & 0.368 & & & & & \\
\hline Downtime before ROSC (min), (IQR) & $10(5-20)$ & $9(5-14)$ & $15(5-42)$ & 0.214 & & & & & \\
\hline Cardiogenic shock, no (\%) & $23(22.8)$ & $14(13.9)$ & $9(8.9)$ & 0.617 & & & & & \\
\hline Acute pulmonary oedema, no (\%) & $9(8.9)$ & $8(7.9)$ & $1(1.0)$ & 0.266 & & & & & \\
\hline
\end{tabular}

post PPCI, there was no difference in mortality amongst the four groups.

STEMI was the most common type of presenting acute coronary syndrome (91\%) (Table 2). Other patients who underwent PPCI had either indeterminate ACS (due to a left bundle branch block) or a high suspicion of an evolving transmural infarct. The majority were in the anterior territory (61\%) and uncommonly involved the right ventricle (5.0\%). Left ventricular (LV) systolic function was depressed in the majority of patients with over $50 \%$ of patients having either moderate or severe LV dysfunction as determined by echocardiography during admission. Only one patient received thrombolytics prior to PPCI. Angiogram was successfully performed in the majority of patients $(98.0 \%)$ with the exception of two patients in whom it was attempted but aborted due to cardiac arrest. There was a high rate of PCI performed (90.1\%). Factors that were statistically associated with reduced survival included severe LV dysfunction, right ventricle (RV) involvement, and the need for intra-aortic balloon pump (IABP) insertion in the cath lab. The indications for IABP insertion in the cath lab included cardiogenic shock, bridge for high risk PCI, and ongoing chest pain. IABP were all inserted prior to admission to ICU. The cardiologic factors did not influence the indication for admission to ICU (Additional file 1: Table S1).

The median duration of stay in the ICU was 3 days (Table 3). Most patients required invasive mechanical ventilation (IMV) (86.1\%) with median duration of IMV being 2 days. The majority of the mortality occurred within the ICU (34 of 37 patients). Significant complications were common with patients suffering major bleeding (9.9\%), infections (31.7\%), acute kidney injury (33.7\%), or in ICU cardiac arrest (6.9\%). Factors that statistically associated with reduced survival included the lack of use of non-invasive ventilation (NIV), inotropes and vasopressor 


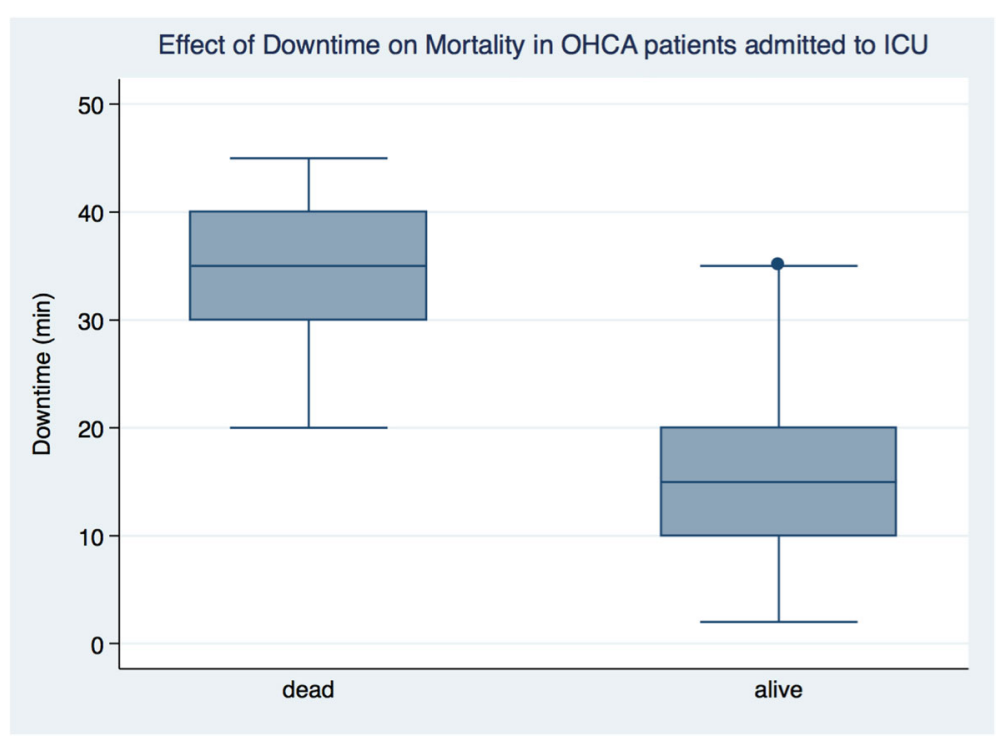

Fig. 2 Box and whisker plots of the effect of downtime on return of spontaneous circulation in OHCA patients

Table 2 Cardiac characteristics of patients admitted to ICU post PPCI. Results are expressed as mean (SD) unless otherwise denoted

\begin{tabular}{|c|c|c|c|c|}
\hline & \multirow[t]{2}{*}{ All Patients } & \multicolumn{3}{|l|}{ Outcome } \\
\hline & & Survivor & Non-survivor & Sign \\
\hline Total number of patients (\%) & $101(100)$ & $67(66.3)$ & $34(33.7)$ & \\
\hline STEMI, no (\%) & $91(90.1)$ & $58(57.4)$ & $33(32.7)$ & 0.158 \\
\hline \multicolumn{5}{|l|}{ MI territory } \\
\hline Anterior, no (\%) & $61(61.0)$ & $42(42.0)$ & $19(19.0)$ & 0.667 \\
\hline Inferior, no (\%) & $38(38.0)$ & $26(26.0)$ & $12(12.0)$ & 1.000 \\
\hline Lateral, no (\%) & $32(32.0)$ & $22(22.0)$ & $10(10.0)$ & 1.000 \\
\hline RV involvement, no (\%) & $5(5.0)$ & $1(1.0)$ & $4(4.0)$ & 0.040 \\
\hline Peak troponin, ng/L med (IQR) & $38.9(13.7-40.0)$ & $26.8(10.9-40.0)$ & $40.0(19.1-626.0)$ & 0.146 \\
\hline \multicolumn{5}{|l|}{ LV systolic function } \\
\hline Normal, no (\%) & $10(11.6)$ & $8(9.3)$ & $2(2.3)$ & 0.488 \\
\hline Mild dysfunction, no (\%) & $26(30.2)$ & $21(24.4)$ & $5(5.8)$ & 0.093 \\
\hline Moderate dysfunction, no (\%) & $22(25.6)$ & $17(19.8)$ & $5(5.8)$ & 0.309 \\
\hline Severe dysfunction, no (\%) & $28(32.6)$ & $14(16.3)$ & $14(16.3)$ & 0.037 \\
\hline Thrombolysis pre-PPCI, no (\%) & $1(1.0)$ & $1(1.0)$ & $0(0.0)$ & 1.000 \\
\hline Angiogram, (successful completion) no (\%) & $99(98.0)$ & $67(66.3)$ & $32(31.7)$ & 0.111 \\
\hline PCl performed (successful completion), no (\%) & $91(90.1)$ & $62(61.4)$ & $29(28.7)$ & 0.298 \\
\hline IABP in cath lab, no (\%) & $50(49.5)$ & $28(27.7)$ & $22(21.8)$ & 0.036 \\
\hline Number of diseased vessels, med (IQR) & $2(1-3)$ & $2(1-3)$ & $2(2-3)$ & 0.514 \\
\hline Left main stem disease, no (\%) & $14(14.1)$ & $8(8.1)$ & $6(6.1)$ & 0.371 \\
\hline TIMI flow, med (IQR) & $3(2-3)$ & $3(2-3)$ & $3(2-3)$ & 0.862 \\
\hline Symptom onset to device time (min, med (IQR) & $210(155-332)$ & $219(159-328)$ & $200(150-350)$ & 0.665 \\
\hline
\end{tabular}


Table 3 Intensive care characteristics and complications of patients admitted to ICU post PPCI. Results are expressed as mean (SD) unless otherwise denoted

\begin{tabular}{|c|c|c|c|c|c|c|c|c|c|}
\hline & \multirow{2}{*}{$\begin{array}{l}\text { All } \\
\text { patients }\end{array}$} & \multicolumn{3}{|l|}{ Outcome } & \multicolumn{5}{|c|}{ Indication for ICU } \\
\hline & & Survivor & Non-survivor & Sign & $\mathrm{OHCA}$ & $\mathrm{IHCA}$ & Card shock & Pulm edema & Sign \\
\hline Total number of patients (\%) & $101(100)$ & $67(66.3)$ & $34(33.7)$ & & $37(36.6)$ & $32(31.7)$ & $23(22.8)$ & $9(8.9)$ & \\
\hline \multicolumn{10}{|l|}{ ICU interventions } \\
\hline Invasive mechanical ventilation, no (\%) & $87(86.1)$ & $56(55.5)$ & $31(30.7)$ & 0.373 & 37 (36.6) & $31(30.7)$ & $12(11.9)$ & $7(6.9)$ & $<0.001$ \\
\hline Duration of IMV, median days (IQR) & $2(1-3)$ & $2(1-2)$ & $2(1-6)$ & 0.314 & $2(2-4)$ & $1(1-2)$ & $2(1-5)$ & $1(1-1)$ & 0.011 \\
\hline Non-invasive ventilation, no (\%) & $25(24.8)$ & $21(20.8)$ & $4(4.0)$ & 0.049 & $7(6.9)$ & $5(5.0)$ & $8(7.9)$ & $5(5.0)$ & 0.047 \\
\hline Duration of NIV, median days (IQR) & $1(1-2)$ & $1(1-2)$ & $2.5(1.5-3)$ & 0.075 & $1(1-1)$ & $2(1-2)$ & $2(1.5-3)$ & $1(1-1)$ & 0.032 \\
\hline Inotropes, median number (IQR) & $1(0-1)$ & $0(0-1)$ & $1(0-2)$ & 0.005 & $1(0-1)$ & $1(0-2)$ & $0(0-1)$ & $0(0-1)$ & 0.617 \\
\hline Vasopressors, median number (IQR) & $0(0-1)$ & $0(0-1)$ & $1(0-1)$ & 0.001 & $0(0-1)$ & $0(0-1)$ & $0(0-1)$ & $0(0-1)$ & 0.971 \\
\hline ECMO, no (\%) & $7(6.9)$ & $1(1.0)$ & $6(5.9)$ & 0.006 & $0(0.0)$ & $7(6.9)$ & $0(0.0)$ & $0(0.0)$ & 0.001 \\
\hline Therapeutic hypothermia, no (\%) & $48(47.5)$ & $33(32.7)$ & $15(14.9)$ & 0.677 & $32(31.7)$ & $14(13.9)$ & $0(0.0)$ & $2(2.0)$ & $<0.001$ \\
\hline IABP, no (\%) & $59(58.4)$ & $35(34.7)$ & $24(23.8)$ & 0.090 & $15(14.9)$ & $23(22.8)$ & $18(17.8)$ & $3(3.0)$ & 0.004 \\
\hline Renal repl therapy, no (\%) & $27(26.7)$ & $10(9.9)$ & $17(16.8)$ & $<0.001$ & $6(5.9)$ & $11(10.9)$ & $8(7.9)$ & $2(2.0)$ & 0.273 \\
\hline \multicolumn{10}{|l|}{ In-hospital complications } \\
\hline Major bleeding, no (\%) & $10(9.9)$ & $6(5.9)$ & $4(4.0)$ & 0.082 & $0(0.0)$ & $7(6.9)$ & $2(2.0)$ & $1(1.0)$ & 0.026 \\
\hline Infections, no (\%) & $32(31.7)$ & $21(20.8)$ & $11(10.9)$ & 1.000 & $13(12.9)$ & $9(8.9)$ & $7(6.9)$ & $3(3.0)$ & 0.936 \\
\hline Renal dysfunction (new onset), no (\%) & $34(33.7)$ & $18(17.8)$ & $16(15.8)$ & 0.048 & $12(11.9)$ & $11(10.9)$ & $9(8.9)$ & $2(2.0)$ & 0.833 \\
\hline In ICU Cardiopulmonary arrest, no (\%) & $7(6.9)$ & $0(0.0)$ & $7(6.9)$ & $<0.001$ & $3(3.0)$ & $4(4.0)$ & $0(0.0)$ & $0(0.0)$ & 0.261 \\
\hline \multicolumn{10}{|l|}{ Outcomes } \\
\hline Duration of ICU stay, median days (IQR) & $3(1-5)$ & $3(1-4)$ & $2(0.5-7)$ & 0.389 & $3(2-7)$ & $2(1-5)$ & $3(0.5-5)$ & $1(0.5-2)$ & 0.095 \\
\hline ICU mortality, no (\%) & $34(33.7)$ & & & & $11(10.9)$ & $13(12.9)$ & $9(8.9)$ & $1(1.0)$ & 0.346 \\
\hline Hospital / 28-day mortality, no (\%) & 37 (36.6) & & & & $12(11.9)$ & $14(13.9)$ & $10(9.9)$ & $1(1.0)$ & 0.265 \\
\hline \multicolumn{10}{|l|}{ Cause of death (of 37 patients) } \\
\hline Treatment withdrawn, no (\%) & $25(67.6)$ & & & & $7(18.9)$ & $9(24.3)$ & $8(21.6)$ & $1(2.7)$ & 0.632 \\
\hline Cardiac Arrest, no (\%) & $7(18.9)$ & & & & $3(8.1)$ & $2(5.4)$ & $2(5.4)$ & $0(0.0)$ & 0.867 \\
\hline Other & $5(13.5)$ & & & & $2(5.4)$ & $3(8.1)$ & $0(0.0)$ & $0(0.0)$ & 0.463 \\
\hline
\end{tabular}

use, transfusion of blood products including red blood cells (RBCs) and nonRBCs, as well as need for extracorporeal membrane oxygenation (ECMO) or renal replacement therapy (RRT). ECMO was used exclusively in patients who suffered IHCA at any point during the ICU admission. Therapeutic hypothermia was used in patients who suffered either OHCA or IHCA in patients with an initial rhythm of ventricular tachycardia or ventricular fibrillation, but was not associated with a statistically significant increase in survival. There were higher than expected rates of bleeding and transfusions (RBC) in the IHCA group.

Twenty-eight-day mortality was similar to ICU mortality (Table 3, 36.6 vs 33.7\%). The cause of death in most patients was withdrawal of care (67.6\%). Post ICU admission cardiac arrest occurred in seven patients $(18.9 \%)$, none of whom survived.

Pre-ICU admission factors that demonstrated a statistically significant difference between survivors and nonsurvivors in univariate analysis were selected for inclusion in multivariable regression analysis. Factors that were independently associated with ICU mortality included high SOFA score and pre-ICU insertion of an IABP (Table 4). Notable factors that were not independently associate with mortality included age, presence of RV dysfunction, and presence of severe LV dysfunction. The odds ratio (OR) for increased mortality for each point increase in SOFA was 1.43 (95\% CI 1.2-1.7). The OR for increased mortality when an IABP was inserted pre-ICU admission (during cardiac catheterization) was 3.38 (95\% CI 1.27-9.03). The sensitivity and specificity of this model was 50 and $91 \%$ respectively with a positive predictive value (PPV) of $73.9 \%$

Table 4 Multivariable logistic regression analysis of factors associated with ICU mortality

\begin{tabular}{llllll}
\hline & Odds ratio & Standard error & $z$ & $P$ value & $95 \% \mathrm{Cl}$ \\
\hline SOFA & 1.43 & 0.127 & 4.01 & 0.000 & $1.200-1.700$ \\
IABP & 3.38 & 1.695 & 2.43 & 0.015 & $1.266-9.030$ \\
\hline
\end{tabular}


and a negative predictive value (NPV) of $78.2 \%$. This model correctly classified $77.2 \%$ of patients in this series and had an AUROC curve of 0.7842 (Fig. 3). When using a model with only SOFA and without IABP, the AUROC was slightly lower (0.75 CI $0.65-0.85)$ in comparison to the model with SOFA and IABP (0.78 CI 0.68-0.89).

\section{Discussion}

In this retrospective observational study, we present a series of consecutive patients post-PPCI pathway that are critically ill and require admission to the ICU for advanced therapies that may only be provided in ICU such as invasive mechanical ventilation or vasoactive support. There is a significant mortality amongst these patients (33.6\%), which is significantly higher than the general PPCI population. Indication for admission (cardiac arrest, pulmonary edema, cardiogenic shock) does not statistically influence mortality and all groups were similar despite their indication. Those patients presenting with higher SOFA scores (reflecting a higher degree of multiple-organ dysfunction), or requiring an IABP during cardiac catheterization were independently associated with higher mortality.

Despite an era of appropriate anti-ischemic therapy post-STEMI and provision of organised and timely reperfusion via $\mathrm{PPCI}$, there remain a proportion of patients who become critically ill and require admission to ICU for invasive monitoring, mechanical ventilation or vasoactive therapy. Patient mortality in this group remains high despite improving outcome for all patients with STEMI presenting for PPCI [3].

In contrast to previous studies of patients requiring mechanical ventilation or suffering from cardiogenic shock following complicated myocardial infarction, our study reviewed consecutive patients admitted to ICU exclusively via the PPCI pathway $[8-13,16,17]$. This included both patients who required mechanical ventilation and those who did not.

A higher SOFA score was associated with increased mortality (Table 4). This suggests that degree of organ dysfunction in patients with complicated myocardial infarction, as with many other critical illnesses, is a major determinant of survival. Surprisingly, neither the requirement for mechanical ventilation nor the indication for admission were independently associated with mortality. To date, no study has described this relationship exclusively in the post-PPCI patient population. A previous study looking at traditional risks scores used in the myocardial infarction population such as the Global Registry of Acute Coronary Events (GRACE) risk score or the Thrombolysis in Myocardial Infarction (TIMI) risk score in comparison with SOFA demonstrated that SOFA provided reasonable discrimination of prognosis [18]. This study was limited, as it did not focus on the post-PPCI population or those patients specifically who were admitted to ICU, which are most likely to be critically ill and potentially benefit from prognostication. Our study is novel as we demonstrate that the SOFA score does predict mortality in this high-risk group of patients admitted to the ICU who require mechanical ventilation and vasopressors. Previous studies looking specifically at patients admitted to ICU with cardiogenic shock demonstrated that there was an association between scores such as Acute Physiology and Chronic Health II/III (APACHE II/III), Simplified Acute Physiology Score II (SAPSII), SOFA and survival outcome $[16,17]$. The specific organ

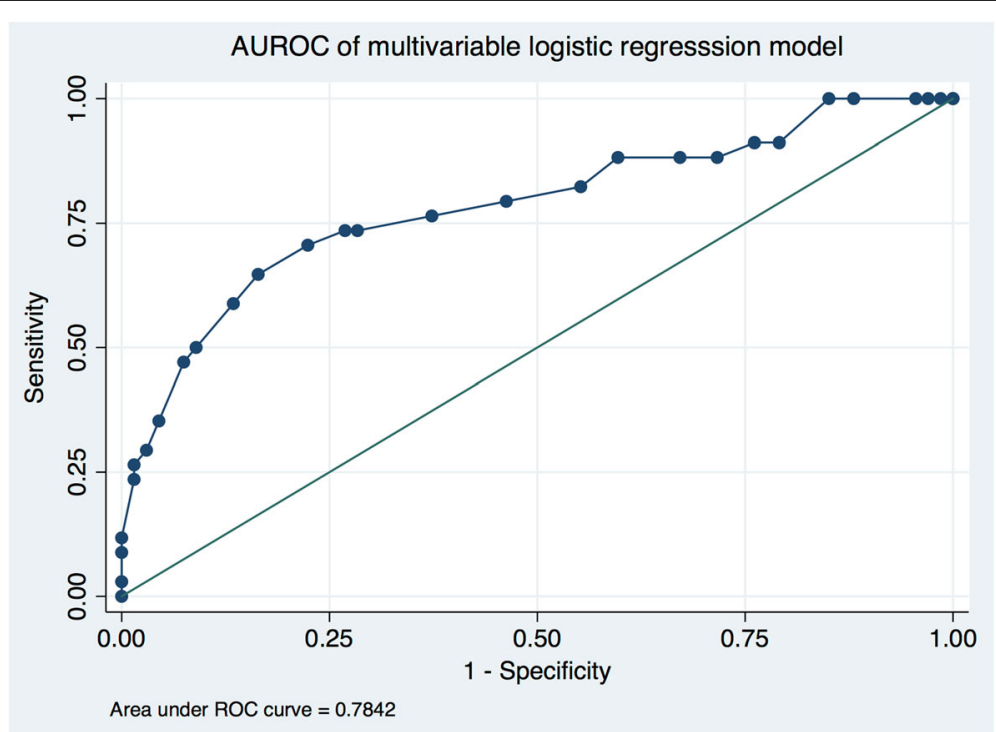

Fig. 3 Area under the receiver operating curver (AUROC) of multivariable logistic regression model using IABP and SOFA 
systems within the SOFA score that were responsible for the higher scores included increased renal dysfunction, lower admission GCS, as well as worse hypoxemia (lower $\mathrm{PaO} 2 / \mathrm{FiO} 2$ ratio (Table 1). The benefit of using SOFA scores and the presence or absence of IABP to prognosticate patients is that it can be easily calculated upon admission to ICU with information routinely available. This is the drawback of scores such as APACHE II/III and SAPSII as they are more complex and time consuming to calculate when compared to SOFA [19]. SOFA was used as a prognostic score due to its simplicity and ability to be calculated with very routine and objective patient data. Retrospective data collection made it difficult to use alternate scores such as APACHE II due to the high number of variables required in these scores including patient historical factors and the risk of missing data [19]. For example, any missing data precluded patients from being included in APACHE II score calculation as per the original description of APACHE II [20]. In addition, it has been demonstrated that there are significant differences in the ability of APACHE II to be calculated accurately when comparing prospective and retrospective collection of data [21]. This further highlights the strength of the SOFA score as it is quick and easy to calculate using commonly available objective clinical data.

We demonstrated that use of IABP was independently associated with mortality which is in keeping with previously reported observational data [22, 23]. The cohort of the study patients who required mechanical circulatory support with IABP and ICU admission was representative of the higher risk patient population and therefore IABP support may have been given to the sicker patients which would induce bias towards poor outcomes in that group. A meta-analysis of cohort studies in the context of STEMI leading to cardiogenic shock supported the use of IABP adjunctive to fibrinolysis [24]. It remains unknown whether early IABP placement can improve clinically important outcomes in patients with STEMI requiring ICU admission.

In the subgroup of patients with an OHCA, a longer down time before ROSC was associated with higher mortality; however, in the multivariable analysis, this was not an independent predictor for increased mortality. The association between prompt ROSC and outcome has been well described previously [25]. Similarly age was a univariate factor associated with increased mortality however was not an independent predictor in the multivariable analysis. It may be that increased age and longer downtimes before ROSC are all reflective of increased likelihood of organ dysfunction and a higher SOFA score, thus not independently associated with mortality.

In the IHCA group, there were five patients who were supported with ECMO under cardiac arrest conditions
(E-CPR). The IHCA group had a high rate of major bleeding most likely associated with the use of E-CPR, as this association is a well described in other ECMO populations [26]. Survival in this group was low which is consistent with previously published reviews on the use of E-CPR in this age demographic [27].

This study had several limitations. It was performed at a single tertiary PPCI referral centre and is retrospective in nature and thus data collection was based on review of the CIS and paper charts. The multivariable logistic regression model was not externally validated in an alternate population or in patients not admitted to ICU. Furthermore, there may be selection bias for patients requiring mechanical circulatory support with IABP due to differences in individual clinical practice patterns.

This study provides a rationale for a future prospective observational study and validation of the multivariable model to determine if this may help triage and prognosticate patients who are not likely to survive post complicated acute myocardial infarction. Potential uses for this type of model include being able to provide prognostic information for care providers and patient family members. It may also help identify patients in whom aggressive care may be deemed unlikely to succeed. Alternatively, if these patients are identified correctly a priori, it may allow a targeted intervention to improve outcomes in this cohort of patients who continue to have an extremely poor outcome.

\section{Conclusions}

Despite only requiring admission $3.5 \%$ of the time to ICU (101 of 2902 patients), those patients suffering an MI that do require ICU post PPCI are very critically ill and have a mortality of $33.7 \%$. The most effective way to prognosticate survival in this cohort of patients is by using the SOFA score, in addition to the requirement for an intra-aortic balloon pump.

\section{Additional file}

Additional file 1: Table S1. Cardiac characteristics of patients admitted to ICU post PPCI by indication. Results are expressed as mean (SD) unless otherwise denoted. (DOCX $17 \mathrm{~kb}$ )

\footnotetext{
Abbreviations

ANOVA: Analysis of variance; APACHE: Acute physiology and chronic health; AUROC: Area under the receiver operating curve; CAD: Coronary artery disease; CCU: Coronary care unit; CIS: Clinical information system; ECMO: Extracorporeal membrane oxygenation; E-CPR: Ecmo during cardio-pulmonary resuscitation; GCS: Glasgow coma scale; IABP: Intra-aortic balloon pump; ICU: Intensive care unit; IHCA: In-hospital cardiac arrest; IMV: Invasive mechanical ventilation; LV: Left ventricle; NIV: Non-invasive mechanical ventilation; NPV: Negative predictive value; OHCA: Out of hospital cardiac arrest; OR: Odds ratio; PF: PaO2:FiO2; PPCl: Primary percutaneous coronary intervention; PPV: Positive predictive value; RBC: Red blood cells; ROSC: Return of spontaneous circulation; RRT: Renal replacement therapy; RV: Right ventricle; SAPSII: Simplified acute
} 
physiology score II; SOFA: Sequential organ failure assessment; STEMI: ST-segment elevation myocardial infarction

\section{Acknowledgements}

Thank Dr. Dan Niven with advice on statistical analysis with this manuscript

\section{Funding}

This research did not receive any specific grant from funding agencies in the public, commercial, or not-for-profit sectors.

\section{Availability of data and materials}

The datasets generated and/or analysed during the current study are not publicly available due to privacy and ethics compliance but are available from the corresponding author on reasonable request.

\section{Author's contributions}

$K P, K J, V M, E B$, and $V Z$ contributed to data collection. KP, VZ, NW, and AV were involved in the study design, statistical methodology, interpretation of results, and writing of the manuscript. All authors read and approved the final manuscript.

\section{Ethics approval and consent to participate}

Ethical approval was obtained from the Papworth Hospital NHS Foundation Trust research and development board for the completion of this study.

\section{Consent for publication}

Not applicable

\section{Competing interests}

The authors declare that they have no competing interests.

\section{Publisher's Note}

Springer Nature remains neutral with regard to jurisdictional claims in published maps and institutional affiliations.

\section{Author details}

'Department of Anesthesia and Intensive Care, Papworth Hospital, Cambridge, England. ${ }^{2}$ Department of Interventional Cardiology, Papworth Hospital, Cambridge, England. ${ }^{3}$ Department of Critical Care Medicine, University of Calgary, ICU Administration - Ground Floor - McCaig Tower, Foothills Medical Center, 3134 Hospital Drive NW, Calgary, AB T2N 5A1, Canada. ${ }^{4}$ Department of Critical Care Medicine, University Hospitals of Birmingham NHS Foundation Trust, Queen Elizabeth Hospital, Birmingham, England

Received: 20 September 2017 Accepted: 18 January 2018

Published online: 25 January 2018

\section{References}

1. Nallamothu BK, Normand SL, Wang Y, Hofer TP, Brush JE Jr, Messenger JC, Bradley EH, Rumsfeld JS, Krumholz HM. Relation between door-to-balloon times and mortality after primary percutaneous coronary intervention over time: a retrospective study. Lancet. 2015;385:1114-22.

2. Keeley EC, Boura JA, Grines CL. Primary angioplasty versus intravenous thrombolytic therapy for acute myocardial infarction: a quantitative review of 23 randomised trials. Lancet. 2003;361:13-20.

3. Shah RU, Henry TD, Rutten-Ramos S, Garberich RF, Tighiouart M, Bairey Merz CN. Increasing percutaneous coronary interventions for ST-segment elevation myocardial infarction in the United States: progress and opportunity. JACC Cardiovasc Interv. 2015;8:139-46.

4. O'Gara PT, Kushner FG, Ascheim DD, Casey DE Jr, Chung MK, de Lemos JA, Ettinger SM, Fang JC, Fesmire FM, Franklin BA, et al. 2013 ACCF/AHA guideline for the management of ST-elevation myocardial infarction: executive summary: a report of the American College of Cardiology Foundation/American Heart Association task force on practice guidelines. Circulation. 2013;127:529-55.

5. de Belder MA, Ludman PF, McLenachan JM, Weston CF, Cunningham D, Lazaridis EN, Gray HH. The national infarct angioplasty project: UK experience and subsequent developments. Eurolntervention. 2014; 10(Suppl T):T96-T104
6. Rotstein Z, Mandelzweig L, Lavi B, Eldar M, Gottlieb S, Hod H. Does the coronary care unit improve prognosis of patients with acute myocardial infarction? A thrombolytic era study. Eur Heart J. 1999;20:813-8.

7. McLenachan JM, Gray HH, de Belder MA, Ludman PF, Cunningham D, Birkhead J. Developing primary $\mathrm{PCl}$ as a national reperfusion strategy for patients with ST-elevation myocardial infarction: the UK experience. Eurolntervention. 2012;8(Suppl P):P99-107.

8. Ariza Sole A, Salazar-Mendiguchia J, Lorente-Tordera V, Sanchez-Salado JC, Gonzalez-Costello J, Moliner-Borja P, Gomez-Hospital JA, Manito-Lorite N, Cequier-Fillat A. Invasive mechanical ventilation in acute coronary syndromes in the era of percutaneous coronary intervention. Eur Heart Acute Cardiovasc Care. 2013;2:109-17.

9. Lopez Messa JB, Andres De Llano JM, Berrocal De La Fuente CA, Pascual Palacin R, Analisis Retraso Infarto Agudo M. Characteristics of acute myocardial infarction patients treated with mechanical ventilation. Data from the ARIAM registry. Rev Esp Cardiol. 2001;54:851-9.

10. Kouraki K, Schneider S, Uebis R, Tebbe U, Klein HH, Janssens U, Zahn R, Senges J, Zeymer U. Characteristics and clinical outcome of 458 patients with acute myocardial infarction requiring mechanical ventilation. Results of the BEAT registry of the ALKK-study group. Clin Res Cardiol. 2011;100:235-9.

11. Zahger D, Maimon N, Novack V, Wolak A, Friger M, Gilutz H, Ilia R, Almog Y. Clinical characteristics and prognostic factors in patients with complicated acute coronary syndromes requiring prolonged mechanical ventilation. Am J Cardiol. 2005:96:1644-8.

12. Lesage A, Ramakers M, Daubin C, Verrier V, Beynier D, Charbonneau P, du Cheyron D. Complicated acute myocardial infarction requiring mechanical ventilation in the intensive care unit: prognostic factors of clinical outcome in a series of 157 patients. Crit Care Med. 2004:32:100-5.

13. Eran O, Novack V, Gilutz H, Zahger D. Comparison of thrombolysis in myocardial infarction, global registry of acute coronary events, and acute physiology and chronic health evaluation II risk scores in patients with acute myocardial infarction who require mechanical ventilation for more than 24 hours. Am J Cardiol. 2011;107:343-6.

14. Vincent JL, Moreno R, Takala J, Willatts S, De Mendonca A, Bruining H, Reinhart CK, Suter PM, Thijs LG. The SOFA (sepsis-related organ failure assessment) score to describe organ dysfunction/failure. On behalf of the working group on sepsis-related problems of the European Society of Intensive Care Medicine. Intensive Care Med. 1996;22:707-10.

15. Vincent $J$, de Mendonca A, Cantraine F, Moreno R, Takala J, Suter PM, Sprung $\mathrm{CL}$, Colardyn F, Blecher $\mathrm{S}$. Use of the SOFA score to assess the incidence of organ dysfunction/failure in intensive care units: results of a multicenter, prospective study. Working group on "sepsis-related problems" of the European Society of Intensive Care Medicine. Crit Care Med. 1998;26:1793-800

16. Kellner P, Prondzinsky R, Pallmann L, Siegmann S, Unverzagt S, Lemm H, Dietz S, Soukup J, Werdan K, Buerke M. Predictive value of outcome scores in patients suffering from cardiogenic shock complicating AMI: APACHE II, APACHE III, Elebute-stoner, SOFA, and SAPS II. Med Klin Intensivmed Notfmed. 2013;108:666-74

17. Popovic B, Fay R, Cravoisy-Popovic A, Levy B. Cardiac power index, mean arterial pressure, and simplified acute physiology score II are strong predictors of survival and response to revascularization in cardiogenic shock. Shock. 2014;42:22-6.

18. Huang SS, Chen YH, Lu TM, Chen LC, Chen JW, Lin SJ. Application of the sequential organ failure assessment score for predicting mortality in patients with acute myocardial infarction. Resuscitation. 2012;83:591-5.

19. Vincent $J$, Moreno R. Clinical review: scoring systems in the critically ill. Crit Care. 2010;14:207.

20. Knaus WA, Draper EA, Wagner DP, Zimmerman JE. APACHE II: a severity of disease classification system. Crit Care Med. 1985;13:818-29.

21. Polderman KH, Girbes AR, Thijs LG, Strack van Schijndel RJ. Accuracy and reliability of APACHE II scoring in two intensive care units problems and pitfalls in the use of APACHE II and suggestions for improvement. Anaesthesia. 2001:56:47-50.

22. Zeymer U, Bauer T, Hamm C, Zahn R, Weidinger F, Seabra-Gomes R, Hochadel M, Marco J, Gitt A. Use and impact of intra-aortic balloon pump on mortality in patients with acute myocardial infarction complicated by cardiogenic shock: results of the euro heart survey on $\mathrm{PCl}$. Eurolntervention. 2011;7:437-41

23. Zeymer U, Hochadel M, Hauptmann KE, Wiegand K, Schuhmacher B, Brachmann J, Gitt A, Zahn R. Intra-aortic balloon pump in patients with 
acute myocardial infarction complicated by cardiogenic shock: results of the ALKK-PCI registry. Clin Res Cardiol. 2013;102:223-7.

24. Sjauw KD, Engstrom AE, Vis MM, van der Schaaf RJ, Baan J Jr, Koch KT, de Winter RJ, Piek JJ, Tijssen JG, Henriques JP. A systematic review and metaanalysis of intra-aortic balloon pump therapy in ST-elevation myocardial infarction: should we change the guidelines? Eur Heart J. 2009;30:459-68.

25. Sasson C, Rogers MA, Dahl J, Kellermann AL. Predictors of survival from outof-hospital cardiac arrest: a systematic review and meta-analysis. Circ Cardiovasc Qual Outcomes. 2010;3:63-81.

26. Cheng R, Hachamovitch R, Kittleson M, Patel J, Arabia F, Moriguchi J, Esmailian F, Azarbal B. Complications of extracorporeal membrane oxygenation for treatment of cardiogenic shock and cardiac arrest: a metaanalysis of 1,866 adult patients. Ann Thorac Surg. 2014;97:610-6.

27. Mendiratta P, Tang X, Collins RT 2nd, Rycus P, Brogan TV, Prodhan P. Extracorporeal membrane oxygenation for respiratory failure in the elderly: a review of the extracorporeal life support organization registry. ASAIO J. 2014; 60(4):385-90.

Submit your next manuscript to BioMed Central and we will help you at every step:

- We accept pre-submission inquiries

- Our selector tool helps you to find the most relevant journal

- We provide round the clock customer support

- Convenient online submission

- Thorough peer review

- Inclusion in PubMed and all major indexing services

- Maximum visibility for your research

Submit your manuscript at www.biomedcentral.com/submit
Biomed Central 